\title{
Aetiology and other features of a cohort of adult Sri Lankans presenting with upper gastrointestinal bleeding (UGIB)
}

\author{
Open access endoscopy experience from a tertiary referral centre
}

\author{
R L Satarasinghe ${ }^{1}$, A P De Silva ${ }^{1}$, K Arulnithy $^{1}$, P D Abeyratne ${ }^{1}$, M A R Jayawardana ${ }^{1}$ \\ Journal of the Ceylon College of Physicians, 2010, 41, 57-60
}

\begin{abstract}
Objectives: To ascertain major causes of UGIB and other related clinical features of adult Sri Lankan using open access endoscopy facilities.

Design and setting: 1500 upper gastrointestinal endoscopies performed by Ward-06, Sri Jayewardenepura General Hospital, Kotte from 01/03/2002 to 01/03/2004 for whatever reason was retrospectively reviewed. Those who had endoscopy for UGIB were selected for the study, and their endoscopy findings and other clinical features analysed.
\end{abstract}

Results: There were 342 (24\%) upper GI bleeders. The mean age of presentation was 55.5 years +/-14.4 SD. A high proportion was seen between 50-70 years of age. Sex distribution was, male:female $=229: 114$ (2:1). $45 \%$ have presented with haematemesis, $31 \%$ with malaena, and $24 \%$ with both. Endoscopy showed the presence of severe antral gastritis and duodenitis, oesophageal varices, oesaphagitis, erosive gastropathy, portal hypertensive gastropathy, pangastritis and peptic ulcer disease in 38\%, 35\%, 28\%, 28\%, $20 \%, 17 \%$ and $15 \%$ of the instances respectively. Hiatus herniae were seen in $43 \%$ although its role was unclear. Often combined pathologies were seen. Only $52 \%$ of the varices showed endoscopic evidence of bleeding. Excess alcohol consumption was seen in 36\% while $5 \%$ were on NSAIDs. $5 \%$ had endoscopic negatives.

Conclusions: UGIB is a major problem to the endoscopist, constituting about $25 \%$ of the work load, in this part of the continent. Although approximately $50 \%$ of the varices found had bled, portal hypertension related pathologies are a cause for concern. Alcohol was a contributory factor in $1 / 3$ of the endoscoped population. Bleeding from PUD was not a dominant feature compared to the west.

\footnotetext{
${ }^{1}$ Sri Jayewardenepura General Hospital, (Postgraduate Tertiary and Teaching), Kotte, Sri Lanka.
}

\section{Introduction}

Acute upper gastrointestinal haemorrhage is a common indication for admission to a hospital. A UK National Audit set by a working group of the British Society of Gastroenterology and the Royal College of Surgeons of England, investigated the epidemiology in a large population based prospective study ${ }^{1}$. The overall incidence is reported as 103 bleeds per 100,000 adults per year, rising from 23 per 100,000 under 30 year olds to 485 per 100,000 in those aged over 75 . There are wide variations in the published mortality rates associated with acute upper GI bleeding ${ }^{2}$. Overall mortality in the National Audit was 14\% and mortality of patients who bled while already hospitalised for other indications was more than double that among those admitted because of their bleed ${ }^{1}$.

In Sri Lanka there are no published large scale studies on the aetiology of acute gastrointestinal haemorrhage. Open access endoscopy facilities are almost non existent in the peripheries at the time of conduct of this study, and there are no rigid regional or national guidelines enforced by the state health services of Sri Lanka, pertaining to management of acute upper $\mathrm{Gl}$ bleeds.

Upper GI bleeding is a common and serious problem and the management is both complicating and challenging ${ }^{3}$. The clinical history and examination at the time of presentation in no way make it possible to elucidate the origin of bleeding ${ }^{4,5,6}$. It is now accepted that fibre-optic endoscopy should be the primary tool of investigation in the case of an upper gastrointestinal haemorrhage $\mathrm{e}^{7,8}$, although it has some important limitations, especially if the bleeding site is in the upper gut $^{9}$. Endoscopy not only offers information on the origin of the bleeding in well over $90 \%$ of patients but also identifies who needs surgical intervention should this become necessary ${ }^{10}$, and delineates a few prognostic factors which are relevant ${ }^{11}$. This study looked into causes of acute upper Gl bleeding in a cohort of adult Sri Lankans, admitted to a medical unit in a tertiary referral centre, over a period of two years, using fibreoptic endoscopy as the first line investigation, on an "open access" basis. 


\section{Subjects and methodology}

Case notes of 1500 patients who had undergone upper gastrointestinal endoscopy for whatever reason, in the principal authors unit SJGH, either admitted or referred, from 01st March 2002 to 1st March 2004 (a two year period) were retrospectively reviewed. Those who had clinical evidence of upper gastrointestinal bleeding (UGIB) in the form of haemotemesis, malena or both were included for the study, and their endoscopic outcome was analysed with other demographic features. Upper gastrointestinal endoscopy was performed within 24 hours to 48 hours of admission following assessment and stabilization, where applicable. As contributory factors, consumption of excess amounts of alcohol, treatment with non steroidal anti-inflammatory drugs (NSAIDs) including low dose aspirin were sought out.

\section{Results}

There were 342 (24\%) upper GI bleeders. The mean age of presentation was 55.5 years+/- 14.4 SD. A high proportion was seen between $50-70$ years of age. Sex distribution was, male: female 229: 114 (2:1). $45 \%, 31 \%$ and $24 \%$ have presented with haematemesis, malena, and both respectively. Endoscopy showed the presence of severe antral gastritis and duodenitis, oesophageal varices, oesaphagitis, erosive gastropathy, portal hypertensive gastropathy, pangastritis and peptic ulcer disease (gastric ulcer $9.6 \%$ and duodenal ulcer $6.4 \%$ ) in $38 \%, 35 \%, 28 \%$, $28 \%, 20 \%, 17 \%$ and $15 \%$ of the instances respectively. Hiatus herniae were seen in $43 \%$ although its role was unclear. Often combined pathologies were seen. Only $52 \%$ of the varices showed endoscopic evidence of bleeding. Excess alcohol consumption was seen in $36 \%$ while $5 \%$ were on NSAIDs. There were no endoscopic negatives. Gastric varices (0.6\%), angiodysplastic lesions (0.6\%), Mallory Weiss tears $(1.2 \%)$, isolated oesophgeal ulcers $(4.1 \% ; 3.8 \%$ related to GORD and 0.3\% post-sclerotherapy) were few in this series. The single most important cause for recurrent bleeding was alcohol abuse.

\section{Discussion}

It is evident from the results that acute upper gastrointestinal bleeding is a major problem amongst acute admissions to a medical ward in Sri Lanka, and in this study $25 \%$ of the total endoscopies performed by the principal author during the said period was to elucidate the aetiology of the upper GI bleeds. Admissions to the surgical units and other medical units with upper gastrointestinal bleeding had not been evaluated in this study. Chronic duodenal and gastric ulcers were the most common causes of upper gastrointestinal bleeding in most of the published studies $^{12,13,14,15}$. In contrast the present study showed peptic ulcer disease in only $15 \%$ of the bleeders. This could well be due to low prevalence rate of Helicobacter pylori in Sri Lanka ${ }^{16,17}$. A postulated explanation for this could be the disappearance of the organism from the gastric mucosa, following initiation of the inflammation process due to low production of and insufficient quantities of urease enzyme by the local strains ${ }^{18}$. In a study pertaining to the demographics of Helicobacter pylori infections and peptic ulcer disease in adult Sri Lankans, Satarasinghe et al found only $2 \%$ of peptic ulcer disease in a cohort of patients who underwent gastroscopy in a secondary referral centre in the Western Province of Sri Lanka over a period of 4 years, with NSAIDs attributable to causation of $1 \%$ of the ulcers $^{17}$. Severe erosive antral gastritis and duodenitis was the commonest cause of upper GI bleeding in this study (45\%). In other published studies duodenal erosions have been reported in $12.4 \%$ and $9.1 \%$ of the instances, by Shennak ${ }^{15}$ and Silverstein et al ${ }^{12}$ respectively, but severe antral gastritis and duodenitis have not been described as sources of upper gastro intestinal bleeding in other published studies. It seems that even in the absence of the true peptic ulceration, severe antral gastritis and duodenitis have been major predisposing factors for acute UGIB in this cohort of patients. What factors influence those lesions to bleed remain largely unknown. In another study of analysis 1200 upper $\mathrm{GI}$ endoscopies performed by the principal author in a secondary referral centre in a Colombo suburb, form 08.03.1997 to 08.03.2001 (4 year period) out of 300 upper GI bleeds, 18\% had had severe antral gastritis and duodenitis ${ }^{19}$. In the study aforementioned, gastric erosions, varices, pangastritis, PUD, and malignancies were noted in $11 \%, 8 \%, 6 \%, 2 \%$ to $0.6 \%$ of the cases respectively. The difference in the endoscopic pathologies is most likely to be due to cohort effect.

Hiatus herniae were seen in $43 \%$ undoubtedly, they could have played a major role in the pathophysiology of GORD. In other published studies, oesophagitis had not been a major source of upper GI bleeding, ranging from about zero percentage ${ }^{13,20}$ to $12.8 \%{ }^{12}$. Oesophageal ulcers were reported in $3.8 \%$, denoting severe GORD, which is a high prevalence compared to other studies ${ }^{12,15}$. Bleeding from erosive antral gastritis (histologically proven), isolated gastric erosions and pangastritis were the major sources of bleeding from acute gastric mucosal lesions (AGML) in $45 \%, 28 \%$ and $17 \%$ respectively in the study. Sugawa et al in their study described AGML being responsible for bleeding in $24 \%$ of instances ${ }^{21}$. In other major published studies gastric erosions have been the major AGML, being $29 \%$ in the ASGE study ${ }^{12}$. Bleeding from erosive antral gastritis and pangastritis had not been described in other published studies. Oesophageal varices were found in $35 \%$ of the bleeders, but only about $50 \%$ of the varices showed evidence of recent bleeding at the time of endoscopy. In comparison it had been responsible in 3.4\% to $15.4 \%$ of the cases in published studies (Table). Mallory 
Weiss tears, seen at the time of endoscopy were $1.2 \%$, which had not been the case in the European study described by Philip et $\mathrm{al}^{20}$. Bleeding from neoplasms has ranked as the lowest, as in all other studies. Angiodysplasia was $0.6 \%$ in the current series and had been variable in other studies ranging from zero percentage to $14.9 \%$ (Table). One was detected with a telangectasia. This patient had Osler-WeberRendur Syndrome. NSAIDs have been incriminated in $5 \%$ of the bleeders, in this study, and had been a major contributory factor in other major studies as well ranging from $15.6 \%$ to $42.2 \%$. The below table gives a comparison of upper gastrointestinal bleeding in other major published studies with the current series.

Overlapping endoscopic pathologies were seen in a significant proportion, contributing to the source of upper GI bleeding. Therefore the endoscopist has a major role in planning out the treatment and the subsequent management at the time of endoscopy. As a result of a lack of endoscopy facilities UGIB is treated with blind blanket therapies, in this part of the world, which is also undoubtedly applicable to many other developing countries.

\section{Table}

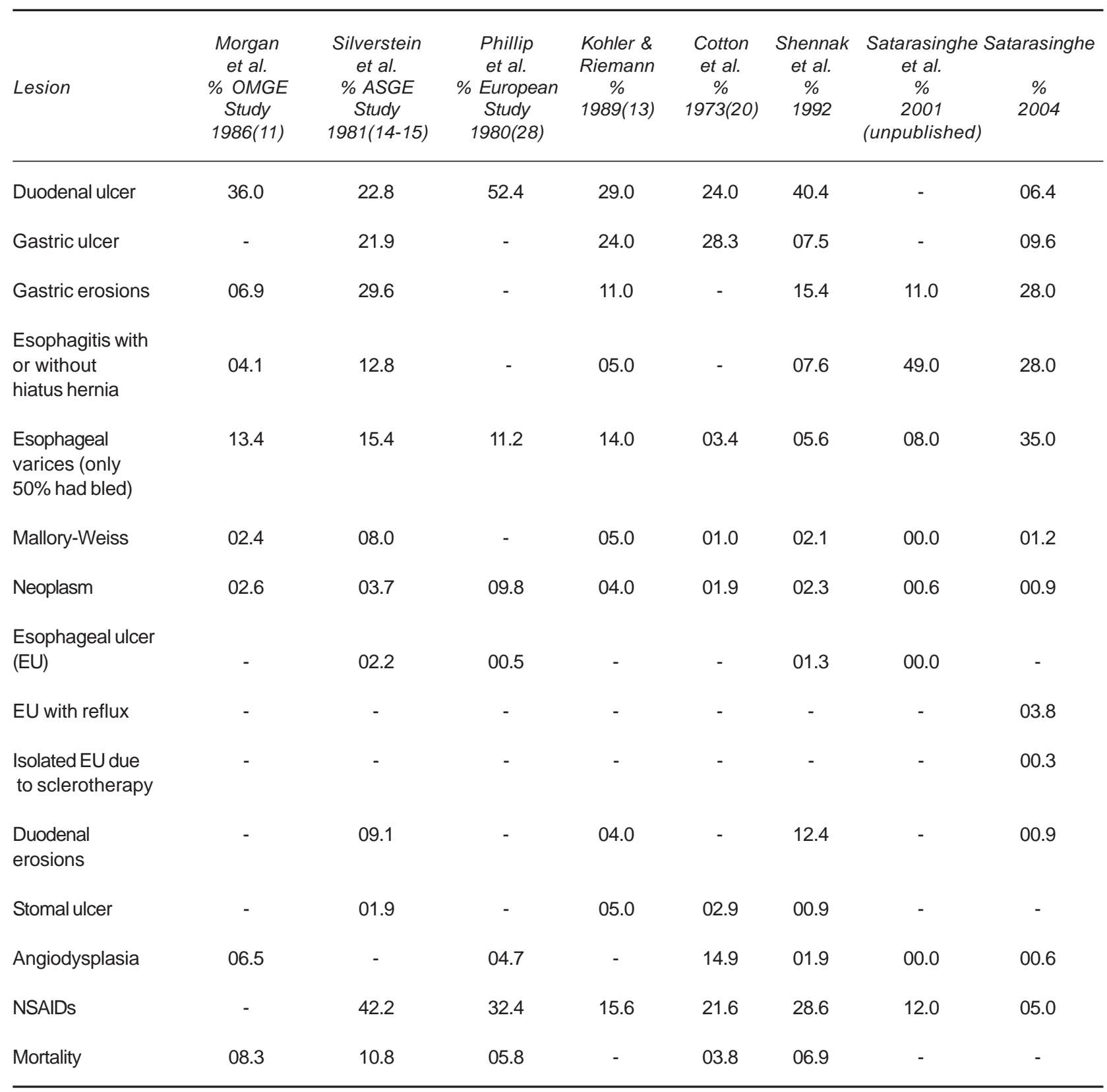




\section{Conclusions}

Upper GI bleeds are a major cause of acute medical admissions in Sri Lanka, which are most of the time treated with blind blanket therapies, due to lack of diagnostic endsocopic facilities and trained personnel. Amongst aetiological lesions of upper GI bleeding, AGML, oesophagitis, and varices had been the major pathologies in this part of the world, in contrast to the West. NSAIDs and alcohol had been important associated contributory factors and there was a clear male preponderance. Finally national and regional guidelines should be formulated based on these observations to educate general public of the contributory factors, mainly alcohol and NSAIDs.

\section{Acknowledgement}

We are extremely grateful to the junior medical officers who have worked in the Medical Unit of Base Hospital Panadura from March 1997 to March 2001, who were actively involved in patient management, staff of the theatre and ICU, for helping at endoscopy and meticulously looking after the Endoscopy Unit. Similarly the hard work done by junior medical officers attached to the unit at Sri Jayewardenepura General Hospital is equally appreciated.

\section{References}

1. Rokall TA, Logans RFA, Devlin HB, et al. Incidence of and mortality from acute upper gastrointestinal haemorrhage in the UK. BMJ 1995; 311: 222-5.

2. Kapur KC, Titley G, Allison MC. Setting quality standards for auditing mortality from upper gastrointestinal haemorrhage. Gastroenterology Today 1998; 8: 3-7.

3. Earnest D. Stomach emergencies. Handbook of gastrointestinal emergencies. Gitnic G. ed Elsevion Science Publishing, New York. NY USA. 1987; 30-88.

4. Lygidakis NJ. Upper gastrointestinal bleeding. Hepatogastroenteral 1991; 38: 195-6.

5. Consensus Conference. Therapeutic endoscopy and bleeding ulcers. JAMA 1989; 262: 1369-72.

6. Watson RC, Porter KG. An audit of hospital admissions to acute upper gastrointestinal haemorrhage. Ulster Med J 1989; 58: 140-4.

7. DagradiAE, Ruiz RA, Weingarten ZG. Influence of emergency endoscopy on the management and outcome of patients with upper gastrointestinal haemorrhage. Am J Gastroenterol 1979; 72: 403-15.
8. Webb WA, McDaniel L, Johnson RC, Doyle HC. Endoscopic evaluations of 125 cases of upper gastrointestinal bleeding. Ann Surg 1981; 193: 624-7.

9. Graham DY. Limited value of early endoscopy in the management of acute upper gastrointestinal bleeding. Ann Surg 1981; 193: 624-7.

10. Miller TA. Emergencies in acid-peptic disease. Gastroenterol Clin N Am 1988; 17: 303-15.

11. Morgan AG, Clamp SE. OMGE international upper gastrointestinal bleeding survey. 1978-1988. Scand J Gastroenterol 1988; 23(Suppl): 551-9.

12. Silverstein FE, Gilbert DA, Tedsco FJ, et al. The national ASGE survey on upper gastrointestinal bleeding. I Study design and baseline data. Gastrointest Endosc 1981; 27: 80-93.

13. Cotton PB, Rosenberg MT, Waldrum RPL, Axon ATR. Early endoscopy of the oesophagus, stomach and duodenal bulb in patients with malena and haematemesis. Br Med J 1973; 2: 505.

14. Forrest JAH, Finlayson NDC, Shearmon DJC. Endoscopy in gastrointestinal bleeding. Lancet 1974; 2: 394-7.

15. Shennak MM. Aetiology of upper gastrointestinal bleeding in Jordanian patients: a prospective study. Ann Saud Medi 1994; 15(1).

16. Fernando N, Perera N, Vaira D, Holton J. Helicobacter pylori in school children from the Western Province in Sri Lanka. Helicobacter 2001; 6(2): 1690174.

17. Satarasinghe RL, Fernando HRR. Demographics of Helicobacter pylori infections and peptic ulcer disease in adult Sri Lankans. A four year endoscopic survey. Do we see a different trend? J Cey Col Phys 2003; 36: 43-6.

18. Satarasinghe RL, Jayamaha DH, Vidyathilake HMS, Siriwardane S. Do our Helicobacter pylori differ from those found in the West, in their ability to produce urease enzyme? A preliminary observation. J Cey Col Phys 2000; 33: 121-3.

19. Satarasinghe RL, Jayamaha $D H$, Samarasinghe I. The profile of upper gastrointestinal bleeds of urban adult Sri Lankan population - an endoscopist's perspective. Proceedings of annual academic sessions of Ceylon College of Physicians 2001 (Unpublished data).

20. Philip J, Clossen M, Gunselmann W. European emergency endoscopy study in abstracts of the IV European Congress of Gastrointestinal Endoscopy. George Thieme Veerlog, Stuttgart, GR 1980.

21. Sugawa C, Steffes CP, Nakamura R, Sferra JJ, et al. Upper GI bleeding in an urban hospital. Etiology, recurrence and prognosis. Ann Surg. 1990; 212(4): 521-6; 526-7. 